\title{
Erratum
}

\section{Visual attention: Race models for selection from multielement displays}

\author{
Claus Bundesen \\ Psychological Laboratory, Copenhagen University, Njalsgade 90, DK-2300 Copenhagen S., Denmark
}

Psychol Res (1987) 49:131-137

1. Line 5 to footnote 1 , p. 116, " $K \geq 12$ " should have read " $K \leq 12$ ".

2. In Line 6 of the same footnoote, " $2 \geq K \geq 12$ " should have read " $2 \leq K \leq 12$ ".

3. On p. 118 , column 1 , lines $7-8$ from the bottom, " $(0 \leq x \leq t)$ " should have been " $(0<x \leq t)$ ". 